\title{
A Narrative Inquiry of the Influence of Canadian Pre-Service Teachers' Chinese Language Learning on Cross-Cultural Learning Through Reciprocal Learning
}

\author{
Yuhan Deng \\ University of Windsor
}

\begin{abstract}
Cross-cultural experience plays a very important role in the growth of preservice teachers. This narrative study explored Canadian pre-service teachers' Chinese language learning and their cross-cultural experiences in China in relation to their participation in a three-month international program between a university in Canada and a university in China. This study focuses on four participants' Chinese foreign language learning and how their Chinese learning influenced their cross-cultural learning when being immersed in a Chinese language environment. The findings show that the pre-service teachers not only developed a basic level of oral language proficiency, but also developed a higher language tolerance for the learners who are non-native speakers of English. In addition, through learning Chinese, the pre-service teachers learned more about Chinese culture and developed an appreciation of different cultures which helped them develop better perceptions and attitudes toward multicultural education in Canada.
\end{abstract}

\section{Introduction}

With cultural diversity and linguistic pluralism underlying multiculturalism in schools around the world, pre-service teachers who will be on the frontiers of the educational practice have to face different challenges in a multicultural educational environment (Banks, 1993). Because they will influence future generations, it is imperative for them to learn to employ multicultural approaches when preparing their classes in the future. Cross-cultural learning and teaching experience can broaden pre-service teachers' worldview and improve their teaching skills. Moreover, incorporating intercultural experience into the pre-service teacher education system can help preservice teachers adapt to the challenges of multiculturalism in their own country (Ateşkan, 2016; Cushner \& Mahon, 2002). 
Over the years, a variety of international teacher preparation programs have benefited preservice teachers to develop their multicultural mindset and global competence (Cushner, 2007; Kabilan, 2013; Thomas, 2006). These programs are usually in the form of study-abroad programs, student exchange programs, short study programs, teaching practicums, immersion programs, or even brief school placements. Research indicates that such experiences are beneficial to the preservice teachers in terms of enhancing their knowledge and skills, world views, and awareness of global issues (Brindley, Quinn, \& Morton, 2009; Kabilan, 2013; Rodriguez, 2011; Unlu, 2015). Most research examined the structure and nature of cross-cultural educational experiences for preservice teachers and affirmed the value of these programs (Cushner \& Mahon, 2002; Quezada \& Alfaro, 2007; Stachowski \& Visconti, 1998; Williams \& Kelleher, 1987; Wilson, 1993) and identified a wide range of benefits. However, there is an increasing recognition of insufficient systematic documentation of pre-service teachers' international experiences (Conle, 2000; Cordeiro, 2007; Zeichner, 2002). Additionally, few studies examine how the pre-service teachers' language acquisition influenced their learning and teaching life in the host country and their subsequent multicultural awareness.

This research is contextualized in Xu and Connelly's (2013) Reciprocal Learning Program (RLP), an international pre-service education program where pre-service teachers from the University of Windsor in Canada and Southwest University in China spend a certain period of time in each other's country to learn about each other's cultures and seek to benefit both educational systems (Xu \& Connelly, 2017). This program was developed by Xu at the University of Windsor with Dr. Shijian Chen at Southwest University in China (2010), and funded through the Social Sciences Humanities Research Council (SSHRC) Partnership Grant Project (Xu \& Connelly, 2013). The purpose of the program is to provide an exceptional experience through border-crossing with international engagement, and to broaden pre-service teachers' teaching horizons in a constantly changing world with increasing societal diversity.

\section{The Purpose of the Study}

Based on the overall goal of the project, the purpose of the current study is to explore the Canadian pre-service teachers' Chinese language learning while participating in the RLP and to understand their cross-cultural experiences during their stay in China. The study also hopes to gain insight into how the Canadian pre-service teachers perceive Chinese culture and how their Chinese learning influences their cross-cultural learning when being immersed in a Chinese language environment. In addition, the study seeks to determine which teaching strategies are most effective and efficient with respect to pre-service teachers' Chinese language acquisition and to identify more useful strategies and suggestions for pre-service teachers' future use.

To achieve these goals, the current study seeks to answer four central research questions:

1. What role does Chinese language learning play in Canadian pre-service teachers' reciprocal learning in China?

2. What are Canadian pre-service teachers' motivations, attitudes, and strategies for learning the Chinese language before departure and during their China visit? 
3. While in China, what language acquisition strategies do Canadian pre-service teachers find most effective?

4. How do Canadian pre-service teachers learn about Chinese culture when immersed in a Chinese language environment?

\section{Literature Review}

\section{Second Language Acquisition and Second Language Learning}

Second language acquisition (SLA) has become a popular topic, attracting increasing interest across the globe since the 1960s (Cook, 2010, Ellis, 1994; Selinker, 1972; Skehan, 1991). SLA refers "both to the study of individuals and groups who are learning a language subsequent to learning their first language as young children" (Saville-Troike, 2006, p. 2), and is the process through which people learn or acquire a language in addition to their native language(s). Although the terms second language learning (SLL) and SLA are used interchangeably in many studies (Gass, 1997), these terms do differ (Ellis, 1994; Krashen, 1981). According to Krashen (1981), SLL refers to the conscious process of learning a second language and spending a certain period of time to learn the language with a specific purpose. Alternately, SLA refers to the acquisition of a language subconsciously or naturally with little or no formal training or learning (Abukhattala, 2013). In addition, SLA is interchangeable with foreign language acquisition (FLA) and foreign language learning (FLL) in some studies (Gass, 1997). Hence, it is necessary to get a better understanding of these relevant key terms.

Second language vs. foreign language. Both second language (L2) and foreign language (FL) describe the languages learned or acquired by people in addition to their first language (L1) (Derakhshan \& Karimi, 2015). In the past, L2 and FL have been used synonymously in many contexts; however, there are some distinctions between the two (Ellis 1994; Stern, 1983). L2 is a language that "somebody learns to speak well and that they use for work or at school, but that is not the language they learned first" (Oxford Advanced Learner's Dictionary, nd). Based on the definition, L2 does not simply refer to "the chronology of language learning"; it also used to indicate "the level of language command in comparison with a primary or dominant language" (Stern, 1983, p. 13). Moreover, Derakhshan and Karimi (2015) address the importance of L2 and its status in a social context. In contrast, Saville-Troike (2006) defines FL as a language that is not commonly used in the learners' immediate social context and notes that most people learn an FL in a formal classroom, often with a specific purpose such as future travel or other cross-cultural communication. Therefore, one of the crucial conditions used to distinguish between an L2 and an FL is to consider whether it owns a good language environment (Moeller \& Catalano, 2015; Ringbom, 1980). Moreover, Stern (1983) states that an FL does not have an official status or an identified function within a country, whereas one's L2 does.

Although SLA and FLA both describe people learning a language in addition to their L1, there are some distinctions between SLA and FLA. SLA should be differentiated from FLA based on the purposes of learning the languages and the learning environment (Hawkins, 2001). As a result of those two factors, learners' learning motivations vary correspondently (Dörnyei, 2008). 
According to Håkansson and Norrby (2010), foreign language learners often show a stronger motivation than L2 learners because of the target language's environmental impact. The environment of L2 learners is better than FL learners, so they learn and acquire the language not only during class, but also from outside of the classroom. Hence, L2 learners show a lower motivation compared to FL learners who basically learn the target language in an environment that lacks regular interactions with the target language community (Ringbom, 1980).

\section{Cross-Cultural Learning and Second Language Learning}

Cross-cultural learning refers to the process of adapting to a new environment and its requirements by gaining necessary knowledge, skills, and attitudes (Hannigan, 1990). Second language learning (SLL) is usually associated with cross-cultural learning; moreover, foreign language learning is also linked with understanding a foreign culture as language and culture cannot exist without each other. An increasing number of studies explore and demonstrate the importance of cross-cultural learning in foreign language learning, business, and other fields (Huang, 2010; Ji, Zhang, \& Nisbett, 2004; Watkins, 2000; Yamazaki \& Kayes, 2004). Kayes, Kayes, and Yamazaki (2005) conducted a literature review research on cross-cultural learning and identified 73 skills, clustered into ten thematic cross-cultural learning competencies. According to Chang et al. (2011), cross-cultural learning research over the past fifty years has primarily focused on the differences between Eastern and Western cultures.

Cross-cultural experience of pre-service teachers. Cross-cultural experience plays an essential role in the growth of pre-service teachers and, when used in conjunction with teaching experience, can broaden teachers' worldview and improve their teaching skills. Moreover, incorporating intercultural experiences into pre-service education can help pre-service teachers adapt to the challenges of multiculturalism in their own country (Ateşkan, 2016). Research indicates that such experiences are valuable to pre-service teachers in terms of enhancing their knowledge and skills, worldviews, and awareness of global issues (Brindley et al., 2009; Kabilan, 2013; Rodriguez, 2011; Unlu, 2015). The programs cover a wide range of issues, and their durations vary from weeks to months. Moreover, some programs may be reciprocal, while others are one-way (Olmedo \& Harbon, 2010; Xu \& Connelly, 2013). Therefore, pre-service teachers' cross-cultural living and studying experiences can differ to some extent.

Numerous pre-service teachers participate in different cross-cultural programs provided by a variety of schools every year (Wilson, 1993). Most research examined the structure and nature of cross-cultural educational experiences for pre-service teachers and affirm the value of these programs and identify a wide range of benefits (Cushner \& Mahon, 2002; Quezada \& Alfaro, 2007; Stachowski \& Visconti, 1998; Williams \& Kelleher, 1987; Wilson, 1993). However, there is an increasing recognition of insufficient systematic documentation of pre-service teachers' international experiences (Cordeiro, 2007; Zeichner, 2002). Because global perspectives gained from cross-cultural experiences will ultimately influence their future students, the current study seeks to develop a more thorough understanding of three phenomena: pre-service teachers' crosscultural living and studying experiences, the ways in which international programs influence their teaching skills, and how study-abroad experiences are meaningful to their lives. 
Chinese as a foreign language learning and teaching. Chinese is the most common language in the world, with 1.28 billion people - approximately $16 \%$ of the world's populationspeaking some form of Chinese as their first language (McCarthy, 2018). In addition, around 70\% of Chinese people speak Mandarin. Chinese is also one of the oldest languages in the world and has been carrying the Chinese culture for thousands of years. According to Saville-Troike (2006) and Stern (1983), Chinese learning and teaching in some countries should be considered foreign language learning and teaching instead of second language. For example, Canada is a linguistically and culturally diverse country that recognizes English and French as its two official languages. Hence, following the arguments put forward by Saville-Troike (2006) and Stern (1983), the current study suggests that the Chinese language should be considered as a foreign language for the preservice teachers. This framing of the language would be more appropriate in the social context. Chinese foreign language learning (CFLL) and Chinese foreign language teaching (CFLT) have aroused an increasing number of researchers' interest in recent decades. Many studies have covered a wide range of research areas: the nature of Chinese language, the approaches and strategies on both CFLL and CFLT, and the influence of Chinese culture on CFLL (Chang, 2017; Chisoni \& Mushangwe, 2015; Moloney \& Xu, 2015; Ramzy, 2006; Taft \& Chung, 1999). One of the biggest differences between Chinese and other kinds of languages is that Chinese is a tonal language. In Mandarin, there are four tones: the rising tone, where the voice raises on the syllable; the departing tone, which drops at the end of the syllable; the level tone that neither drops nor raises on a syllable; and the checked tone, which drops in the middle of the syllable and then raises at the end. Pronouncing one syllable with each tone will give that syllable four different meanings in Mandarin, though in English the meaning would remain constant regardless of the tone being used. Moreover, unlike the phonetic Latin alphabet used in English, Chinese uses logographic characters which cannot be read phonetically (Taft \& Chung, 1999). These characters are comprised of radicals, which are a graphical component of the larger logographic character. Using radicals as teaching tools can be helpful in the context of CFLL. As language and its culture are inseparable, it is vital to understand the importance of culture in second language learning and its significant influence on CFLL (Mushangwe \& Chisoni, 2015).

CFLL motivation. Motivation is a key factor in foreign language learning and has been studied for many years. Norris-Holt (2001) defines motivation as the orientation of a learner with respect to the goal of learning a second language and divides it into integrative motivation and instrumental motivation. Instrumental motivation would lead to a significant effort in learners' second and foreign language learning, thus achieving a greater language competence (Dörnyei, 1990, 1998; Veronica, 2008). Moreover, learner's attitudes and motivation are both important for second language acquisition (Dörnyei, 2001).

Ruan, Duan, and Du (2015) suggest that Chinese is often regarded as a difficult language to learn in Western countries and argue that it is therefore necessary to increase the motivation of learners - especially for beginners with low language skills - when conducting a task-based class. Rueda and Chen (2005) purport that cultural differences can influence the assessment of motivational processes in second and foreign language learning. This is validated by $\mathrm{Yu}$ and Watkins (2008), who conclude that learners from Western countries and learners from Asian 
countries are significantly different in terms of their motivation for learning Chinese as a second language. Motivation plays an essential role in learning CFL; students could easily lose their interest in Chinese learning if appropriate teaching methods and criteria are not effectively utilized to stimulate their motivation (Hettiarachchi, 2016; Mkize \& Chisoni, 2015). Moreover, not only can intrinsic motivational factors such as cultural interest promote CFLL, but so too can external conditions such as learning environment, teachers, and peers influence CFLL learners (Yan, 2012).

\section{Theoretical Framework}

Mezirow's (1991) transformative learning theory has been used to analyze how pre-service teachers engage in cross-cultural learning and teaching programs in many different countries (Cushner \& Mahon, 2002; Östermark, 2011, Trilokekar \& Kukar, 2011). According to Mezirow (1991), transformative learning involves being critically aware of one's own assumptions and how they shape the ways in which people perceive, understand, and feel about the world. Challenging these structures can facilitate more inclusive and integrative perspective that reduces discrimination. Trilokekar and Kukar (2011) argue that this lens provides a way of seeing how pre-service teachers make meaning as they engage in learning and teaching activities abroad.

O'Sullivan (2003) defines transformative learning as a process that involves "a deep, structural shift in the basic premises of thought, feelings, and actions" (p. 327) and fosters a dramatic shift in the way people view their relationship in the world. This shift involves five aspects: a) how people understanding themselves and their locations; b) how they understand their relationships with others and the natural world; c) their awareness of their bodies; d) their sense of justice and happiness; and e) their understanding of power relations in intersectional structures of class, race, and gender. A thorough review of the literature on transformative learning suggests that pre-service teachers are depicted through a self-designed conceptual map (see Figure 1).

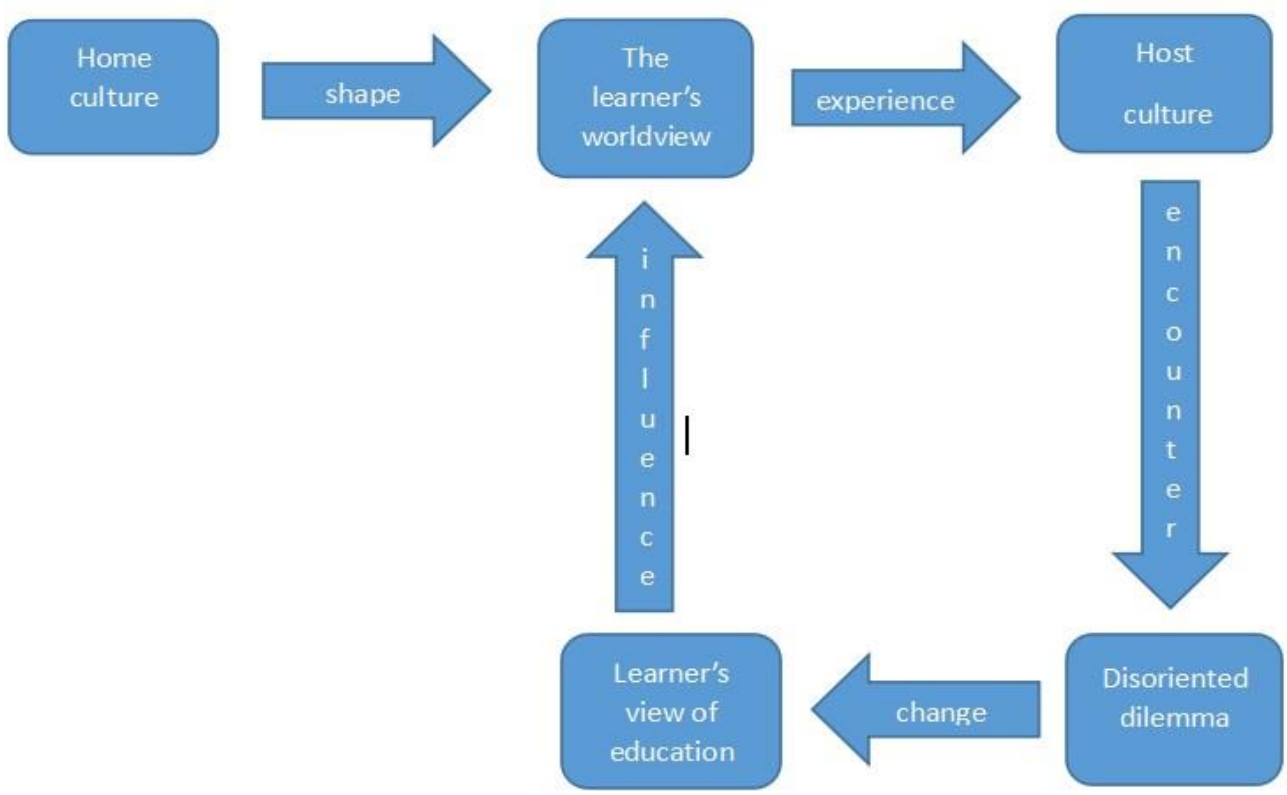

Figure 1. Transformative learning process of the pre-service teachers. 
Home culture shapes pre-service teachers' perspectives, framing the way they see the world. After entering a different cultural context, they encounter a disoriented dilemma to some extent (Taylor, 1998). This cross-cultural learning experience can change their views on education and challenge their opinions of their own values, intelligence, and potential. At the end of the transformative learning process, pre-service teachers should ideally form a new worldview that will impact their future life and work.

\section{Methodology}

\section{Narrative Inquiry}

Narrative inquiry is a qualitative methodology that studies "the ways humans experience the world" (Connelly \& Clandinin, 1990, p. 2). It is based on the premise that people understand or make sense of their lives through narrative (Bruner, 1991). The many definitions of narrative inquiry all have one common element: storytelling. Connelly and Clandinin (1990) argue that "humans are storytelling organisms who, individually and socially, lead storied lives" (p. 2). In short, people live with stories. In the development of narrative research, Xu and Connelly (2009) define narrative inquiry as "a way of thinking about life" (p. 221) that is not simply telling stories. In other words, narrative inquiry refers to understanding and inquiring into experiences through a "collaboration between researcher and the participants, over time, in the place or series of places, and in social interaction with milieus" (Clandinin \& Connelly, 2000, p. 20). Moreover, a narrative inquiry is "more than the uncritical gathering of stories" (Trahar, 2009, para. 1). This is supported by Xu and Connelly (2010), who state that "story is not so much a structured answer to a question, or a way of accounting for actions and events, as it is a gateway, a portal, for narrative inquiry into meaning and significance" (p. 356). Thus, narrative inquiry is defined not simply by storytelling, but by the critical reflection and analysis of stories that offer insights into the practical experience of people immersed in the social context of a given subject.

Narrative inquiry is an ideal methodology for education research as it explores pedagogical issues by analyzing the experiences of individuals. Connelly and Clandinin (1990) were the first to provide an overview of narrative inquiry in educational research. Dewey (1938) discusses that life is education, emphasizing the importance of experiential education. Based on his theory of experience, Clandinin and Connelly (1990) claim that there is a strong connection between life, experience, and education. This promoted the development of narrative inquiry as an approach of studying individual stories. An increasing number of narrative studies have analyzed specific domains of education, such as music education, mathematics education, and pre-service teacher education. In this way, practitioners were no longer "silenced in the research relationship" (Clandinin \& Connelly, 1990, p. 4). Moreover, practitioners, "who may also become coresearchers" (Huber, Caine, Huber, \& Steeves, 2013, p. 220), have more space to talk about their own experiences. Besides interviews, journals, self-reflections, field notes, and other records can be used as methods to conduct a narrative inquiry.

Suitability. According to Conle (2000), narrative inquiry focuses more on the individual stories rather than a border view. This applies to the participants of the current study, who have 
unique experiences and stories from visiting China. Every pre-service teacher who attends the program holds different understandings and expectations with regard to this trip to China. In addition, they have displayed different degrees of motivations, attitudes, and strategies while learning the Chinese language. Given these factors, the experiences of the participants might be transcribed quite differently. Thus, narrative inquiry will be an effective approach with respect to pre-service teachers' cross-cultural experiences through their own stories.

\section{Research Procedure}

As a member of the RLP, the researcher visited China with the group of pre-service teachers for three months. Before departure, the pre-service teachers had attended nine weekly planning sessions starting in January 2018, during which they had taken regular Chinese language classes. After receiving approval from the Research Ethics Board (REB) and consent from the participants, the researcher focused on observing the participants' Chinese language and cultural learning during their stay in China. At the end of the trip, individual interviews with the participants and follow-up Chinese language assessments were conducted after receiving additional consent from them.

Participants. In this study, participants were pre-service teachers studying at the University of Windsor who applied to the RLP in 2017-2018. Although they come from the same program, they differ with respect to cultural heritage, major, learning background, and teaching experience. All individuals had their own unique experiences. Ten pre-service teachers participated in the Reciprocal Learning Program from March 2018 to June 2018. Four pre-service teachers are showcased in this study, pseudonymously called Jamie, Carmen, Linda, and Tony. Jamie and Carmen are both Caucasians, while Linda was originally born in Pakistan and immigrated to Canada when she was young. Tony was born in Canada, though his parents immigrated to Canada from Vietnam. All four participants are Canadian citizens.

Research methods. Five research methods are implemented in this study: a) pilot Chinese language proficiency assessments, b) participant observations, c) field notes, d) individual interviews, and e) post-Chinese language proficiency assessments.

\section{Findings}

\section{Pilot-Language Assessment}

The week prior to departure, the four participants did the language assessment during class. The participants first needed to match Chinese greeting words with the correct English meanings. Then, they needed to distinguish Chinese characters from 0 to 10. Lastly, they needed to match Chinese words with the corresponding pictures. It took approximately 10 minutes for the participants to complete the assessment, which was conducted in both English and Chinese. The result turned out fairly well. All the participants did well on the Chinese greeting words and were able to recognize the Chinese characters from 0 to 10 with the help of Pinyin. Jamie and Carmen had the most answers correct. However, two participants did not do as well. Tony thought that some of the words looked familiar to him, but he just could not remember them during that assessment. Linda, 
who had low expectations for the assessment, was happy with the result because she knew that she had been able to learn some Chinese words during the three months (Linda, personal communication, 2018).

\section{Jamie's Stories}

Jamie explained this trip was an "eye-opening" experience for him (Jamie, personal communication, 2018). He had learned a lot within the three months. While learning Mandarin, Jamie showed a high level of motivation during the initial lessons before departure, and also showed a positive attitude towards learning Mandarin throughout this trip. He engaged in many public situations where he could learn and practice Mandarin. He initially started utilizing the knowledge he gained in the Chinese classes to communicate with a Mandarin-speaking flight attendant while he was on the plane from Toronto to Beijing, though other group members were still in English-speaking mode. One of the reasons that Jamie had been interested in learning Mandarin was that his brother used to teach English in China several years before Jamie joined the RLP. Jamie explained "I think I'm interested [in learning Mandarin] because my brother speaks Chinese" (Jamie, personal communication, 2018). Not only had he been influenced by his brother, but he was also fascinated by Marxism in China.

However, Jamie also reported that his motivation "went up and down" (Jamie, personal communication, 2018) during this trip. He mentioned that his busy schedule and the stress associated with it caused his learning motivation to fluctuate during the trip:

I had higher motivation, even my Dad even sent me an email like a week ago being like 'You should come back and take a year to learn Chinese in China,' but... [My motivation] was really high at the start, and then went down in the middle, and it's back up by practicing a little more, but it was not enough. It went down. I think it was because I felt a little bit overwhelmed after the trip. Maybe I am overwhelmed by being in a new country. (Jamie, personal communication, 2018).

After arriving in China, Jamie continued to learn Mandarin by himself. He asked his Chinese friends to help him practice Mandarin. He also helped the Southwest University students with their English and asked them to help with his Chinese. He said that he should have asked for help from the Chinese students more. In addition, Jamie used digital language applications extensively during the three months in China, and he used WeChat, a Chinese social media application, to practice Mandarin. During our interview, Jamie showed the learning apps on his cell phone and articulated how much he had achieved with one of the apps. He said: "I have been using Pleco as an English-Chinese dictionary, and sometimes I used HelloChinese. Actually, I have gone pretty far with it. I have learned the clothes, directions, some food, time, and dates." (Jamie, personal communication, 2018)

Jamie also shared his experience about how learning Chinese helped him teach the English language to the Chinese students: 
It has been helpful like in the school, the students will come up to you and ask you a lot of questions. Like I will say, “我是历史老师 (I am the History teacher).” Even I say it poorly, but they like hearing small things like that a lot. So it has been helpful for Canadian teachers connecting with students. The students seem[ed] to like [it] a lot when I said “非常好 (very good)!”...I think maybe it helps the students [to be] willing to take more risks to learn English, and it maybe helps to lighten the class because sometimes the students are very shy when there is a foreign teacher in the class...It improves the relationship between me and the students. I can tell that the teachers also appreciate[d] it. Definitely, it could help get closer with that. (Jamie, personal communication, 2018)

\section{Carmen's Stories}

Carmen initially considered English to be an international language and Chinese to be unnecessary, but she changed her attitude towards learning Mandarin after staying in China:

I think we didn't realize the importance of our survival lessons of Chinese until we came here. English is kind of a snobby language and...we just assumed that everyone knows English because it's so 'universal'...So, we just assumed that people in China would speak English...and it's funny because we didn't really appreciate how much the survival lessons were going to help us. I brought my book of all the survival lessons in Chinese, and it's funny how I review it now, and I see how many words were used and how much we struggled the first month-and-a-half and we didn't know how to even say “我要 (I want)”, or “这个 (this)” and “那个 (that)". We did not realize that we needed to know that! And now looking back, it's like by using all these words, and if I just focused on the beginning, then I feel like I could have learned a lot more here. I think the survival lessons were so much more important than we assumed they were. And I wish that we would have appreciated them more before we were living in China. (Carmen, personal communication, 2018)

Motivated by external and pragmatic factors, Carmen also came to realize the flaws of her own Anglo-centric perspective. This highlights how being immersed in a foreign culture can promote transformative learning with regard to cultural sensitivity and awareness. In addition, she noted that her motivation was inhibited to some degree by the difficulty of Mandarin, but she observed that her motivation became stronger after she came to China:

I have motivation because I know that I am good at learning languages, but I say that because I was good at high school French class. It's easy to get discouraged when learning Chinese. It's discouraging because it's so hard. Like “我要” and "I want". Nothing there connects the two. So, you just straight memorize it, like really 
learn it and understand it. So even if I had the motivation, it is easy to lose it just because of how different the language is. I still want to learn it especially now that I have that base of a few words. Dr. Xu told me that 'If you can learn 300 words in Chinese, you can read the newspapers; you can probably have a solid conversation.' It is funny because it is true that there are words that I learned “今天”, that I learned on my own... So I feel I am more motivated now that we are about to learn which I did not have before, and that is interesting. (Carmen, personal communication, 2018)

Carmen's insights emphasize how learning motivation can be inhibited by the difficulty of learning a language that does not use a phonetic alphabet, like English does, or that does not share commonalities with Latinate languages, as French does. However, her narrative also demonstrates how these challenges can be overcome by becoming immersed in the culture of the target language, which is an essential component of CFL approaches.

\section{Linda's Stories}

Although Linda was dedicated to participating all the RLP activities and motivated to visit China, she did not make much effort to learn Mandarin during the prep sessions. She confirmed this herself in the individual interview at the end of the trip. During the interview, she said that she did not learn much Mandarin from the survival Chinese lessons because she was tired from her tight course schedule in Canada. In addition, she had been more interested in Japanese and Korean, so she was not dedicated to learning Mandarin at the beginning. However, she started changing her attitude towards learning Mandarin when staying in China, and she became more confident after learning more Mandarin and made more Chinese friends:

That's something that has surprised me. Because I was kind of happy with my Korean, my Chinese is slowly getting better, and I have made good friends with the kind university students...I used to be shy in Canada... but I become more social now in China... Before I was more interested in learning Japanese and Korean. I didn't really want to learn Chinese, but now that I've learned some of it, I don't want to lose what I have. I actually am interested in keeping this language. (Linda, personal communication, 2018)

Due to her low level of motivation, Linda did not learn much initially; however, after discovering her love for romantic dramas, I recommended several Chinese romantic dramas to her. She started to watch the Chinese dramas and enjoyed the stories immensely. The more Linda watched, the more she became interested in learning Mandarin. During the interview with Linda, she explained her language learning process:

I started to listen to the dramas. I watched dramas and that helped me because listening is how I learned. I watch shows. For example, I pick up the words “你在 
哪里呀?” which means “Where are you?” I learned it through a drama. (Linda, personal communication, 2018)

Being immersed in the culture of the target language is a critical component of a CFL approach, and Linda's experience seems to validate this claim and underscores how such approaches can increase internal motivation.

Linda did not use language applications to learn Mandarin when she was in China. Instead, she found that asking friends nearby was an effective way to improve her Mandarin. In addition, consistent repetition and practice could enhance the knowledge she gained. During the interview, Linda said:

When we first met [a Chinese student], I could not say her name at all. In the beginning, I just called her by her English nickname, and then I started calling her [Chinese name]. Now, it's so easy for me, not because I hear it more, but because my tongue and my mouth are able to say and move in a way that Chinese words require. I know the four different tones. I have been practicing and practicing. For me, the learning method has always been listening to someone doing it, and saying it constantly with my friends... When I was saying something wrong, Tony would fix me, I learned it right...And then I talked to Tony, he would say something wrong, and I would fix him. (Linda, personal communication, 2018)

Linda's response not only reinforces Carmen's narrative, which underscores the value of friendship with the Chinese speakers, but also highlights the value of peer learning. When peers engage in learning together, they can build on each other's knowledge.

\section{Tony's Stories}

Because of Tony's Vietnamese background, he had a better understanding of Asian cultures than other participants did, and he knew more about China than they did. However, he did not show a strong interest in learning Chinese. During the interview, Tony said that he had a good memory, which helped his language learning. Also, because he was bilingual, he was familiar with second language learning. Tony's ability to quickly pick up the tones and accents gave him more confidence than the others. Though he attended the classes, he did not learn any Mandarin after class or practice Mandarin in the WeChat group before departure.

Unlike Jamie and Carmen, Tony did not demonstrate a strong motivation to learn Mandarin during the initial lessons. As he can quickly pick up the tones and accent, he was more confident than the others. In addition, Tony believed that with the help of technology, he was able to communicate with local people more efficiently:

It's more motivation to survive, basically...Again, I know language won't be that big of a deal because I'll find ways to work around it...The thing I used the most is 
my phone...looking things up on Pleco or Google Translate. (Tony, personal communication, 2018)

Tony had no intrinsic motivation to learn Mandarin, and with apps on his phone helping him engage with locals, neither did he have the external motivation to learn the language. Thus, even though he intuitively learned some of the Chinese language with greater ease than the other participants, he made little progress overall at the beginning of the trip. However, after living and learning in China, Tony found many Chinese people assumed he was also Chinese many times due to his Asian appearance. As a result, he had more opportunities to communicate with local people, which increased his learning motivation slightly. Moreover, helping teach other preservice teachers some new Mandarin words that he learned from the locals also increased his motivation to some extent.

While being interviewed, Tony, who completed a school placement at the same primary school as Jamie, shared a similar perspective:

My Chinese, it helps my school practicum with...connecting. Students can make connections, but like even outside of the classroom, a way of teaching students like words and phrases in English because always make soon interaction like a teaching moment, right? So I didn't know what [the Chinese word for] a Frisbee was, so I showed it to the students, [and] the [students were] like “飞盘”, “oh, 飞盘, I am learning it now." A great connection with the students, especially outside of the classroom. I will say we have a good time. (Tony, personal communication, 2018)

\section{Post-Chinese Language Proficiency Assessment}

The participants completed a post-Chinese language proficiency assessment after returning to Canada. Overall, all the participants did very well on the assessment. For the speaking part, the participants were asked to answer four simple questions related to greetings, their teachable subjects, their basic impressions about China, and the food they liked in China. All the participants were able to answer these questions in Chinese. However, some of the questions were repeated two or three times at the request of the participants. When the participants were asked to write down at least five Chinese characters on the paper, not all the participants did very well in their written assessment. For the last part, the participants needed to match the Chinese words with the corresponding pictures. However, because Pinyin was not displayed, they had to identify Chinese characters, and that proved challenging for the participants.

The post-language assessment demonstrated that the participants had developed a higher oral language proficiency since their departure. It also validated the participants' claims that they did not put much effort into learning Chinese characters. Because the participants focused mainly on developing their listening and speaking skills when they were in China, they were only able to write a few Chinese characters. Therefore, the tests results illustrated that the participants maintained their pre-departure understanding of Chinese characters. Though they may have become more familiar with the Chinese characters during their stay in China, they were not able 
to write these words correctly. Another significant finding is that the participants relied excessively on Pinyin to remember the Chinese words. Therefore, they barely recognized the Chinese characters without Pinyin.

\section{Discussion}

\section{The Role of Participants' Chinese Language Proficiency in China}

Chinese language learning plays a significant role in the participants' reciprocal learning in China. Learning Chinese as a foreign language helps pre-service teachers develop their interpersonal skills (Ateşkan, 2016; Kabilan, 2013; Yang, 2011; Zhao, Meyers, \& Meyers, 2009). It enhanced the participants' intrapersonal and interpersonal skills, which allowed them to have deeper and more meaningful interactions with the local communities. For example, at the beginning, the intention of learning the Chinese language helped the participants easily start a conversation with the locals, such as the teachers and students from Southwest University, the teachers and students from the local placement schools, administrators, and support staff. During the learning process, the participants had more opportunities to build close relationships with the local communities so that they could have a deeper understanding of each other. The intimate relationships between the participants and the locals encouraged the participants to keep learning Chinese. All the participants said that speaking with their local friends gave them opportunities to practice Mandarin without the fear of making mistakes. Moreover, Jamie and Linda have decided to go back to China to teach Chinese students and to keep learning Mandarin.

In addition, learning Chinese as a foreign language promotes interaction and engagement within the pre-service teachers' group members (Kabilan, 2013; Zhao et al., 2009). A democratic learning environment was created by the pre-service teachers when they stayed in China. They not only shared the knowledge of Mandarin they learned in terms of new words or important phrases they believed; they also discussed new ideas about teaching EFL, teaching plans, and other aspects of learning. This deepened their knowledge of other specific issues and skills. For example, Linda claimed that she learned some useful Mandarin from the group members when they had a discussion together and she felt that the interaction in such a context was beneficial. Therefore, the interactions among the pre-service teachers and between them and the local community enriched the pre-service teachers' practices and experiences with regard to their interpersonal skills (Zhao et al., 2009).

\section{Learning Motivations}

The study's findings reveal that the participants' motivation varied from person to person. Jamie and Carmen showed strong motivations before coming to China; however, Linda and Tony did not demonstrate strong motivations to learn Mandarin before departure. Though all the participants showed strong learning motivations when they first arrived in China, their motivations fluctuated throughout the three-month trip in China. The study's findings also reveal that the participants only focused on their spoken Mandarin instead of learning the Chinese logographic alphabet. This was likely the result of two factors. The first is that the Chinese logographic alphabet 
is very different from Western phonetic alphabets (Taft \& Chung, 1999; Wang \& Shiau, 1973). Thus, unlike the English language, the Chinese characters cannot be read phonetically. Hence, learning Chinese characters involves a lot of rote memorization (Winke, 2013; Xiao, 2002) and it becomes more difficult for English natives to learn Chinese. Moreover, because the participants of this study were not taught the Chinese characters in a systematic way, they did not understand the structure of the Chinese characters and the radicals (Taft and Chung, 1999). The second reason is that pre-service teachers' motivations for learning Mandarin are primarily based on survival needs (Norris-Holt, 2001), which means that they are different from the normal foreign language learners. They learned Mandarin primarily to make living and studying in China easier during the three months. Chinese characters are used for written language, which the participants did not need for most of their interactions. Thus, it was not imperative for all the teacher candidates to learn Mandarin, and it did not influence their academic performance if they did not learn. Therefore, the participants tended to only focus on learning oral speaking for the daily necessity instead of practicing reading and writing. In the end, the intimate relationships between the participants and the locals intrigued the participants' motivations to keep learning Chinese.

\section{Cross-Cultural Experience}

The three-month cross-cultural experiences of the four participants can be considered a process of transformative learning (Mezirow, 1991; O'Sullivan, 2003). When the participants initially arrived in China, they started the transformative learning process. They experienced "a deep, structural shift in the basic premises of thought, feelings, and actions" (Maxwell, 2002, p. 18). The findings suggest that all the participants encountered a disorienting dilemma to some extent after arriving in China. The participants' comments reveal that, while staying in China, they faced a wide range of adaptation, such as language barriers, cultural differences, and different eating habits. The time that the participants spent in China made them look at China, Chinese people, and Chinese culture from a different perspective. Before this trip, the participants held some negative attitudes or stereotypes regarding certain features of the Chinese education and culture. More positive attitudes towards the structure of society and the Chinese educational system took shape in their minds during this international trip. They addressed the importance of being exposed to a new international environment, which facilitated the hands-on experience they gained through opportunities to observe local schools, teach ESL classes, and attend cultural seminars. This is consistent with Dunn, Dotson, Cross, Kesner, and Lundahl (2014), whose participants shared structurally similar narratives. The stories shared by the participants also indicate that the overseas learning and teaching experience challenged their opinions of their own values, intelligence, and potential, thereby transforming their views on education and allowing them to form a new and more inclusive worldview (Mezirow, 1991; O’Sullivan, 2003).

\section{Conclusion}

The current study explores both the cross-cultural experiences of Canadian pre-service teachers in China and their Chinese language learning while participating in the RLP between Canada and 
China. The current research also reveals the importance and benefits of learning Chinese as a foreign language for the pre-service teachers' cross-cultural experiences and their professional and personal development. The narratives in the current study offer critical insights into the participants' attitudes towards learning Mandarin and their learning motivations, which allows one to identify the various strategies that facilitate language learning among the pre-service teachers. Moreover, it provides insights into how the participants perceived Chinese culture when they were immersed in a Chinese language environment. The findings from this study indicate that preservice teachers' cross-cultural immersion experience provided them with insights into different cultures that benefited their future teaching career (Ateşkan, 2016; Kabilan, 2013; Rodriguez, 2011; Unlu, 2015). In addition, they encountered different obstacles and challenges, such as language barriers and culture shock during the transformative learning process (Dunn et al., 2014). More importantly, through the RLP, the participants were able to visit China where they developed themselves personally and professionally over their three-month exchange. As Connelly and $\mathrm{Xu}$ (2015) state, the reason that cultural exchange programs between China and Canada exist in the contexts of post-secondary learning in both Canada and China is that "the Chinese have things to learn educationally from the Canadians and, reciprocally, that the Canadians have things to learn educationally from the Chinese" (p. 2). Moreover, Xu and Connelly (2017) illustrate the concept of reciprocal learning and emphasize the importance of reciprocity in teacher education between Canada and China. This suggests that the overseas immersion experience of pre-service teachers is reciprocal for both local communities and themselves.

\section{References}

Abukhattala, I. (2013). Krashen's five proposals on language learning: Are they valid in Libyan EFL classes. English Language Teaching, 6(1), 128-131. https://doi.org/10.5539/eltv6n1p128

Ateşkan, A. (2016). Teacher candidates' cultural and teaching experiences abroad. Journal of Education for Teaching, 42(2), 135-148. https://doi.org/10.1080/02607476.2016.1144634

Banks, J. A. (1993). Multicultural education: Development, dimensions, and challenges. Phi Delta Kappan, 75(1), 22-28.

Brindley, R., Quinn, S., \& Morton, M. L. (2009). Consonance and dissonance in a study abroad program as a catalyst for professional development of teacher candidates. Teaching and Teacher Education, 25(3), 525-532. https://doi.org/10.1016/j.tate.2008.09.012

Bruner, J. (1991). The narrative construction of reality. Critical Inquiry, 18(1), 1-21. https://doi.org/10.1086/448619

Chang, L., Mak, M. C., Li, T., Wu, B. P., Chen, B. B., \& Lu, H. J. (2011). Cultural adaptations to environmental variability: An evolutionary account of East-West differences. Educational Psychology Review, 23(1), 99-129. https://doi.org/10.1007/s10648-010-9149-0

Chang, L. P. (2017). The development of the test of Chinese as a foreign language (TOCFL). In D. Zhang \& C. H. Lin (Eds.), Chinese as a second language assessment (pp. 21-41). Singapore: Springer.

Chisoni, G., \& Mushangwe, H. (2015). Evaluating the impact of the use of the internet on learning Chinese by students from the Confucius Institute of the University of Zimbabwe. Journal of Technology and Chinese Language Teaching, 6(1), 25-42. https://doi.org/10.17265/1539$\underline{8080 / 2015.02 .009}$ 
Clandinin, D. J., \& Connelly, F. M. (2000). Narrative inquiry: Experience and story in qualitative research. San Francisco, CA: Jossey Bass.

Conle, C. (2000). Narrative inquiry: Research tool and medium for professional development. European Journal of Teacher Education, 23(1), 49-63.

Connelly, F. M., \& Clandinin, D. J. (1990). Stories of experience and narrative inquiry. Educational Researcher, 19(5), 2-14. https://doi.org/10.3102/0013189X019005002

Connelly, F. M., \& Xu, S. J. (2015, May). Reciprocal learning: Comparative models and the partnership project. Paper presented at the International Conference on Reciprocal Learning and Symbiotic Relationships in School Development, East China Normal University, Shanghai, China.

Cook, V. J. (2010). The relationship between first and second language acquisition revisited. In E. Macaro (Ed.), The continuum companion to second language acquisition (pp. 137-157). London, UK: Continuum.

Cordeiro, P. A. (2007). A modest proposal for the improvement of scholarship in internationalizing teacher education. Teacher Education Quarterly, 34(1), 151-154.

Cushner, K. (2007). The role of experience in the making of internationally-minded teachers. Teacher Education Quarterly, 34(1), 27-39. Retrieved from http://www.jstor.org/stable/23478850

Cushner, K., \& Mahon, J. (2002). Overseas student teaching: Affecting personal, professional, and global competencies in an age of globalization. Journal of Studies in International Education, 6(1), 44-58. https://doi.org/10.1177/1028315302006001004

Derakhshan, A., \& Karimi, E. (2015). The interference of first language and second language acquisition. Theory and Practice in Language Studies, 5(10), 2112-2117.

Dewey, J. (1938). Experience and education. New York, NY: Kappa Delta Pi.

Dörnyei, Z. (1990). Conceptualizing motivation in foreign-language learning. Language Learning, 40(1), 45-78. https://doi.org/10.1111/j.1467-1770.1990.tb00954.x

Dörnyei, Z. (1998). Motivation in second and foreign language learning. Language Teaching, 31(3), $117-$ 135. https://doi.org/10.1017/S026144480001315X

Dörnyei, Z. (2001). New themes and approaches in second language motivation research. Annual Review of Applied Linguistics, 21, 43-59.

Dunn, A. H., Dotson, E. K., Cross, S. B., Kesner, J., \& Lundahl, B. (2014). Reconsidering the local after a transformative global experience: A comparison of two study abroad programs for preservice teachers. Action in Teacher Education, 36(4), 283-304. https://doi.org/10.1080/01626620.2014. $\underline{948227}$

Ellis, R. (1994). The study of second language acquisition. Oxford, UK: Oxford University Press.

Gass, J. D. (1997). Stereoscopic atlas of macular diseases: Diagnosis and treatment (4th ed.). Maryland Heights, MO: Mosby.

Håkansson, G., \& Norrby, C. (2010). Environmental influence on language acquisition: Comparing second and foreign language acquisition of Swedish. Language Learning, 60(3), 628-650. https://doi.org/10.1111/j.1467-9922.2010.00569.x

Hannigan, T. P. (1990). Traits, attitudes, and skills that are related to intercultural effectiveness and their implications for cross-cultural training: A review of the literature. International Journal of Intercultural Relations, 14(1), 89-111. https://doi.org/10.1016/0147-1767(90)90049-3

Hawkins, R. (2001). The theoretical significance of universal grammar in second language acquisition. Second Language Research, 17(4), 345-367. https://doi.org/10.1177\%2F026765830101700404

Hettiarachchi, H. K. (2016). A study on student motivation in learning Chinese as a foreign language in Sri Lanka and effective teaching strategies. In Proceedings of the International Conference on Foreign Language Teaching and Learning, (pp. 198-201). Department of Modern Languages, Faculty of Humanities, University of Kelaniya, Colombo, Sri Lanka. 
Huang, L. (2010). Cross-cultural communication in business negotiations. International Journal of Economics and Finance, 2(2), 196-199. https://doi/org/10.5539/ijef.v2n2p196

Huber, J., Caine, V., Huber, M., \& Steeves, P. (2013). Narrative inquiry as pedagogy in education: The extraordinary potential of living, telling, retelling, and reliving stories of experience. Review of Research in Education, 37(1), 212-242. https://doi.org/10.3102/0091732X12458885

Ji, L. J., Zhang, Z., \& Nisbett, R. E. (2004). Is it culture or is it language? Examination of language effects in cross-cultural research on categorization. Journal of Personality and Social Psychology, $87(1), 57-65$.

Kabilan, M. K. (2013). A phenomenological study of an international teaching practicum: Preservice teachers' experiences of professional development. Teaching and Teacher Education, 36, 198-209. https://doi.org/10.1016/j.tate.2013.07.013

Kayes, D. C., Kayes, A. B., \& Yamazaki, Y. (2005). Essential competencies for cross-cultural knowledge absorption. Journal of Managerial Psychology, 20(7), 578-589. https://doi.org/10.1108/0268394051 0623399

Krashen, S. D. (1981). Second language acquisition and second language learning. Oxford, UK: Oxford University Press.

McCarthy, N. (2018, February 12). The world's most spoken languages. Statista. Retrieved from: https://www.statista.com/chart/12868/the-worlds-most-spoken-languages/

Mezirow, J. (1991). Transformative dimensions of adult learning. San Francisco, CA: Jossey-Bass.

Mkize, F., \& Chisoni, G. (2015). The role of motivation in learning Chinese as a second language: a case study of Zimbabwean students learning Chinese as a second language. International Journal of Language and Linguistics, 3(4): 252-257. https://doi.org/10.11648/j.ijll.20150304.19

Moeller, A. J., \& Catalano, T. (2015). Foreign language teaching and learning. In J. D. Wright (Ed.), International encyclopedia for social and behavioral sciences (2nd ed., vol. 9), (pp. 327-333). Oxford, UK: Pergamon Press.

Moloney, R., \& Xu, H. (2015). Transitioning beliefs in teachers of Chinese as a foreign language: An Australian case study. Cogent Education, 2(1), 1-10. https://doi.org/10.1080/2331186X.2015. $\underline{1024960}$

Mushangwe, H., \& Chisoni, G. (2015). A critical analysis of the use of pinyin as a substitute of Chinese characters. Journal of Language Teaching and Research, 6(3), 685-694. https://doi.org/10.1080/ $\underline{01443410601061306}$

Norris-Holt, J. (2001). Motivation as a contributing factor in second language acquisition. The Internet TESL Journal, 7(6), 1-7.

Olmedo, I., \& Harbon, L. (2010). Broadening our sights: Internationalizing teacher education for a global arena. Teaching Education, 21(1), 75-88. https://doi.org/10.1080/10476210903466992

Östermark, E. L. (2011). Intercultural sojourns as educational experiences: A narrative study of the outcomes of Finnish student teachers' language-practice periods in Britain. Scandinavian Journal of Educational Research, 55(5), 455-473. https://doi.org/10.1080/00313831.2010.537687

O'Sullivan, E. (2003) Bringing a perspective of transformative learning to globalized consumption. International Journal of Consumer Studies, 27(4), 326-330. https://doi.org/10.1046/j.14706431.2003.00327.x

Quezada, R. L., \& Alfaro, C. (2007). Biliteracy teachers' self-reflections of their accounts while student teaching abroad: Speaking from" the other side". Teacher Education Quarterly, 34(1), 95-113. https://doi.org/10.1016/S0346-251X(99)00032-9

Ramzy, A. (2006, June). Get ahead, learn Mandarin. Time Magazine. Retrieved from http://content.time.com/time/world/article/0,8599,2047305,00.html 
Ringbom, H. (1980). On the distinction between second-language acquisition and foreign language learning. Paper presented at the Nordic Conference on Applied Linguistics, Hanasaari, Espoo, Finland. Retrieved from https://files.eric.ed.gov/fulltext/ED269973.pdf

Rodriguez, E. (2011). What teacher candidates bring home when they travel abroad: Rethinking teaching through a short international immersion experience. Scholar-Practitioner Quarterly, 5(3), 289-305. Retrieved from https://files.eric.ed.gov/fulltext/EJ974356.pdf

Ruan, Y., Duan, X., \& Du, X. Y. (2015). Tasks and learner motivation in learning Chinese as a foreign language. Language, Culture and Curriculum, 28(2), 170-190. https://doi.org/10.1080/07908318. $\underline{2015.1032303}$

Rueda, R., \& Chen, C. B. (2005). Assessing motivational factors in foreign language learning: Cultural variation in key constructs. Educational Assessment, 10(3), 209-229. https://doi.org/10.1207/ $\underline{\text { s15326977ea1003 } 4}$

Saville-Troike, M. (2006). Introducing second language acquisition. Cambridge, UK: Cambridge University Press.

Second language. (n.d.). In Oxford Advanced Learner's Dictionary. Retrieved from https://www.oxfordlearnersdictionaries.com/definition/english/second-language

Selinker, L. (1972). Interlanguage. International Review of Applied Linguistics in Language Teaching, 10, 209-232. https://doi.org/10.1515/iral.1972.10.1-4.209

Skehan, P. (1991). Individual differences in second language learning. Studies in Second Language Acquisition, 13(2), 275-298. https://doi.org/10.1017/S0272263100009979

Stachowski, L. L., \& Visconti, V. A. (1998). Service learning in overseas nations: US student teachers give, grow, and gain outside the classroom. Journal of Teacher Education, 49(3), 212-219. https://doi.org/10.1177\%2F0022487198049003007

Stern, H. H. (1983). Fundamental concepts of language teaching. Oxford, UK: Oxford University Press.

Taft, M., \& Chung, K. (1999). Using radicals in teaching Chinese characters to second language learners. Psychologia, 42(4), 243-251. https://doi.org/10.3389/fpsyg.2017.01846

Taylor, E. W. (1998). The theory and practice of transformative learning: A critical review. Retrieved from https://calpro-online.org/eric/docs/taylor/taylor_00.pdf

Trahar, S. (2009, January). Beyond the story itself: Narrative inquiry and autoethnography in intercultural research in higher education. Qualitative Social Research, 10(1). 1-13. https://doi.org/10.17169/fqs$\underline{10.1 .1218}$

Trilokekar, R. D., \& Kukar, P. (2011). Disorienting experiences during study abroad: Reflections of teacher candidates. Teaching and Teacher Education, 27(7), 1141-1150. https://doi.org/10.1016/j.tate.2011.06.002

Unlu, I. (2015). Teacher candidates' opinions on Erasmus student exchange program. Educational Sciences: Theory and Practice, 15(1), 223-237. https://doi.org/10.12738/estp.2015.1.2176

Veronica, A. C. (2008). Motivation in language learning. Paper presented at the 2nd International Multidisciplinary Scientific Conference on Social Sciences and Arts. https://doi.org/10.5593/ SGEMSOCIAL2015/B12/S3.085

Wang, P. P., \& Shiau, R. C. (1973). Machine recognition of printed Chinese characters via transformation algorithms. Pattern Recognition, 5(4), 303-321.

Watkins, D. (2000). Learning and teaching: A cross-cultural perspective. School Leadership \& Management, 20(2), 161-173. https://doi.org/10.1080/13632430050011407

Williams, L., \& Kelleher, R. (1987). International student teaching: Linkage for change. Innovative Higher Education, 11(2), 84-93. https://doi.org/10.1007/BF00889766 
Wilson, A. H. (1993). Conversation partners: Helping students gain a global perspective through crosscultural experiences. Theory into Practice, 32(1), 21-26. Retrieved from www.jstor.org/stable/ $\underline{1476478}$

$\mathrm{Xu}$, S. J. (2011). Bridging the East and West dichotomy: Harmonizing Eastern learning with Western knowledge. In J. Ryan (Ed.), Understanding China's education reform: Creating cross-cultural knowledge, pedagogies and dialogue (pp. 224-242). London, UK: Routledge.

Xu, S. J., Chen, S., \& Huang, J. (2015). Pedagogies of working with diversity: West-East reciprocal learning in preservice teacher education. In L. Orland Barack \& C. J. Craig (Eds.), International teacher education: Promising pedagogies (part B), (pp. 137-160). Emerald Group.

Xu, S. J., \& Connelly, F. M. (2009). Narrative inquiry for teacher education and development: Focus on English as a foreign language in China. Teaching and Teacher Education, 25(2), 219-227. https://doi.org/10.1016/j.tate.2008.10.006

$\mathrm{Xu}$, S. J., \& Connelly, F. M. (2010). Narrative inquiry for school-based research. Narrative Inquiry, 20(2), 349-370.

Xu, S., J. \& Connelly, F. M. (Project Directors) (2013). Reciprocal learning in teacher education and school education between Canada and China. Social Sciences and Humanities Research Council of Canada (SSHRC) Partnership Grant 2013-2020 [Grant 895-2-012-1011].

Xu, S. J., \& Connelly, F. M. (2017). Reciprocal learning between Canada and China in teacher education and school education: Partnership studies of practice in cultural context. Frontiers of Education in China, 12(2), 135-150. https://doi.org/10.1007/s1151

Yamazaki, Y., \& Kayes, D. C. (2004). An experiential approach to cross-cultural learning: A review and integration of competencies for successful expatriate adaptation. Academy of Management, 3(4), 362379. https://doi.org/10.5465/AMLE.2004.15112543

Yan, H. (2012). Motivation of Chinese language learners: A case study in an intermediate Chinese class (Unpublished masters thesis). University of Massachusetts-Amherst, Amherst, MA. Retrieved from https://scholarworks.umass.edu/theses/963/

Yang, C. C. (2011). Pre-service English teachers' perceptions of an overseas field experience programme. Australian Journal of Teacher Education, 36(3), 92-104. https://doi.org/10.14221/ajte.2011v36n3.4

Yu, B., \& Watkins, D. A. (2008). Motivational and cultural correlates of second language acquisition. Australian Review of Applied Linguistics, 31(2), 17-1. https://doi.org/10.2104/aral0817

Zeichner, K. (2002). Beyond traditional structures of student teaching. Teacher Education Quarterly, 29(2), 59-64. Retrieved from http://www.jstor.org/stable/23478291

Zhao, Y., Meyers, L., \& Meyers, B. B. (2009). Cross-cultural immersion in China: Preparing preservice elementary teachers to work with diverse student populations in the United States. Asia-Pacific Journal of Teacher Education, 37(3), 295-317. https://doi.org/10.1080/13598660903058925

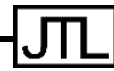

